\title{
Heat Balance Study on Glacier AX010 in Shorong Himal, East Nepal*
}

\author{
Tetsuo Ohata** and Keiji Higuchi**
}

\begin{abstract}
A heat balance study was done on the small glacier AX010 in Shorong Himal under weather conditions of air temperature (ave. $2.3^{\circ} \mathrm{C}$ ), low humidity (ave. $7.0 \mathrm{mb}$ ), low wind speed (ave. $1.2 \mathrm{~m} / \mathrm{sec}$ ) and high cloud amount. For the whole observation period, the percentage of each component to the heat income was $87 \%$ for net radiation, $12 \%$ for sensible heat, and $1 \%$ for latent heat.
\end{abstract}

\section{Introduction}

A heat balance study was conducted on the small glacier AX 010 in Shorong Himal, East Nepal in the summer season of 1978 , in order to investigate the process of ablation and the factors determining the amount of ablation on the glaciers in the Nepal Himalayas. As the ablation season corresponds to the summer monsoon season the effect of this typical weater was also taken into consideration. The Glacier AX 010 is located on the south side of Mt. Numbur (Higuchi et al., 1978). The observation period lasted 18 days from June 11 to June 29, 1978.

Other simultaneous studies were done on the same glacier throughout the summer season. The mass balance is reported by Ageta et al. (1980), the variation of albedo of the glacier surface by Ohata et al. (1980) and the ice temperature by Tanaka et al. (1980). Therefore, this heat balance study was a part of the comprehensive study done on the mass-heat balance of a glacier in this region.

2. The site of observation and instrumentation

A map of the glacier is shown in Fig. 1 . The length of the glacier is $1.5 \mathrm{~km}$, the terminus is at the height of $4952 \mathrm{~m}$ and the highest point is $5360 \mathrm{~m}$. The site of the observation was situated nearly in the middle of the ablation area at the height of $5030 \mathrm{~m}$ as shown by $\mathrm{HB}$ in Fig. 1. The

* Glaciological Expedition of Nepal, Contribution No. 67

** Water Research Institute, Nagaya University, Nagoya 464, (Present affiliation of $T$. Ohata: National Institute of Polar Research, Tokyo 173). inclination of the glacier surface at the site was $7^{\circ}$.

The instruments were arranged to obtain the sensible and latent heat fiux by the profile method. A $4 \mathrm{~m}$ pole was set at the site. The scene of the observation site is shown in Fig. 2.

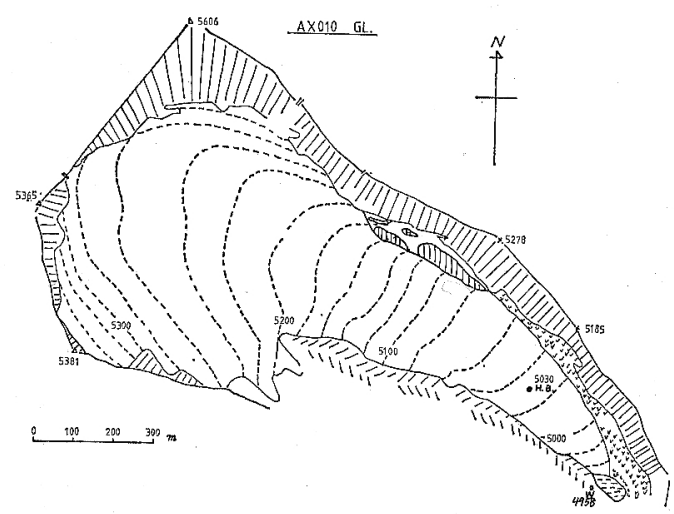

Fig. 1. The map of Glacier AX010. The observation site is shown by HB.

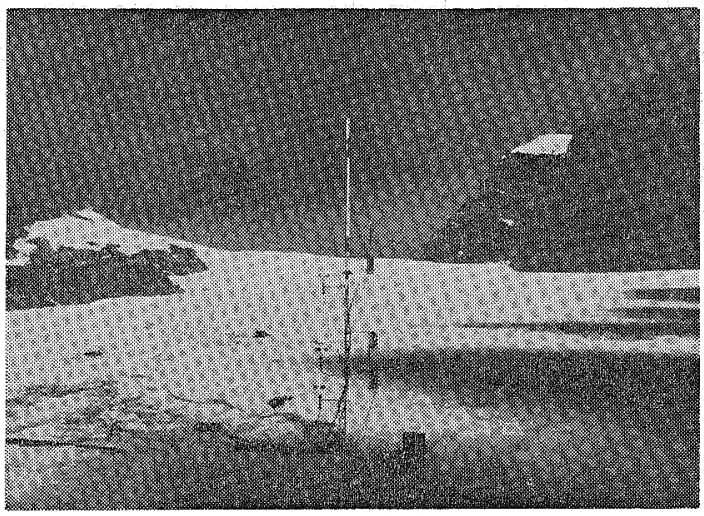

Fig. 2. Photograph of the observation site. The picture is looking upstream. 
Wind speed was measured by 3 cup type an- radiation was measured by a pair of pyranometers. emometers in which the rotating time is measured with a photoelectric sensor. Four anemometers The amount of cloud was estimated by eye meawere placed at heights of $0.5,0.9,1.7$ and $3.2 \mathrm{~m}$ surement.

above the glacier surface on the average. This

Ablation was measured by the lowering of type of anemometer starts to rotate at a critical wind speed of $0.2 \mathrm{~cm} / \mathrm{sec}$, which can be considered as quite sensitive. The number of rotations was totalled for a 30-minute period to obtain the average wind speed.

the ice surface relative to the bottom of drilled holes that were $40 \mathrm{~cm}$ deep on the average. Measurements were made every morning and evening. The density of snow was measured by a density sampler when the glacier ice was covered by snow.

Snow or ice temperature was measured at the

Air temperature was measured by a platinum resistance thermometer placed in an aspirating shelter. These were set at the same levels as the anemometers. Wet bulb temperature was measured by a platinum resistance thermometer covered by a wet gauze inside the same aspirating shelter. Water was supplied to the gauze from the water tank attached to the shelter.

depth of $1 \mathrm{~cm}$ by a platinum resistance thermometer. It was reset every evening.

\section{Meteorological conditions during the observation period}

The summer climate of the Nepal Himalaya region is warm and moist due to the monsoon climate which usually starts at the beginning of

The global solar radiation and the reflected solar June and ends in the middle of September. In

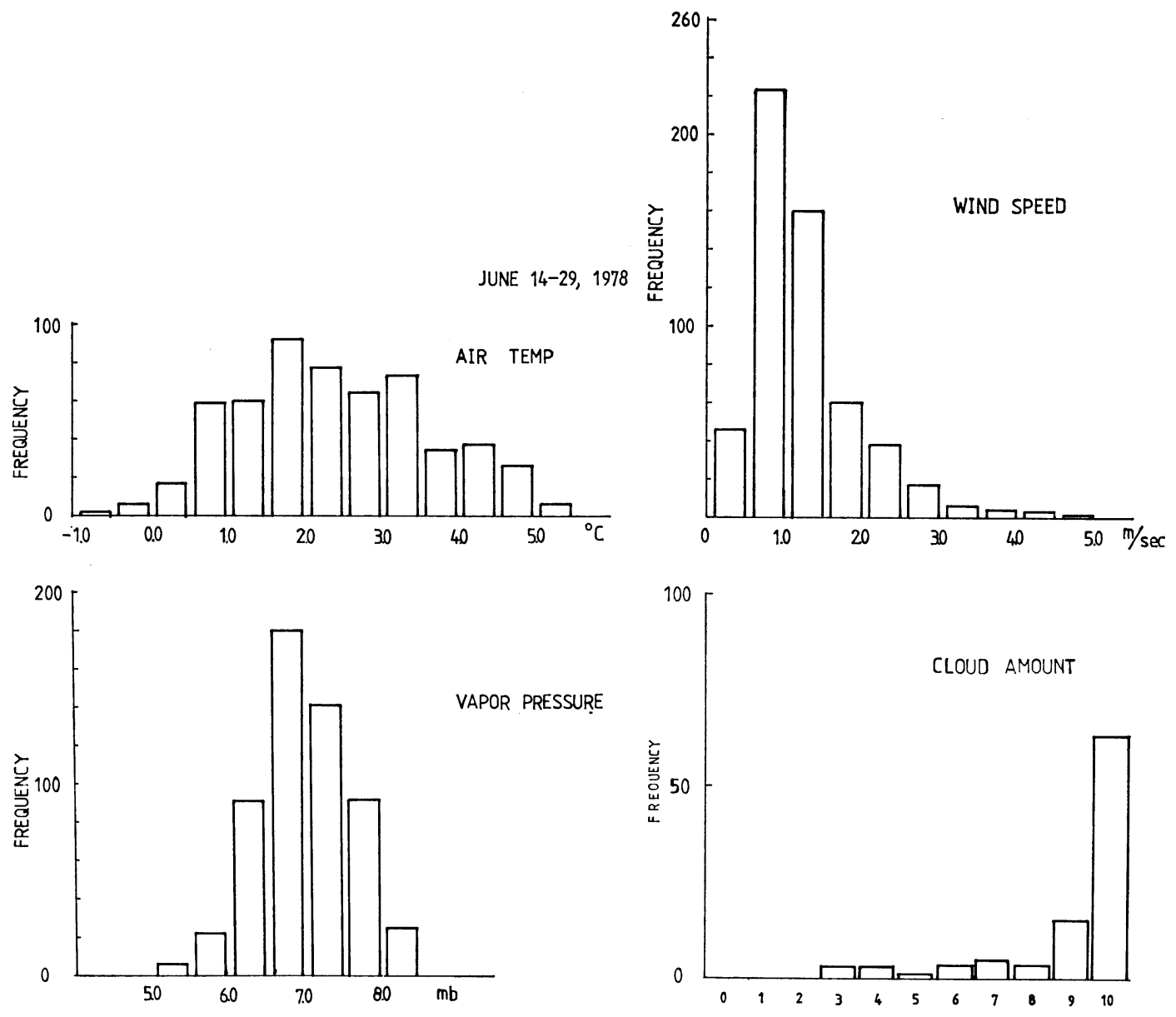

Fig. 3. The frequency distribution of air temperature, vapour pressure, wind speed and cloud amount at the observation site during June 14-29. 
1978 the monsoon started around June 5 in this area, determined from the data of air temperature and cloud amount. Thus the period when the present observation was made was at the beginning of the monsoon season.

In Fig. 3, the frequency distributions of air temperature, vapor pressure, wind, speed and cloud amount are shown. The period under consideration is June 14-29, and 30-minute average data is used for air temperature, vapor pressure and wind speed. The air temperature ranged between -1.0 and $5.5^{\circ} \mathrm{C}$, and the average value was $2.3^{\circ} \mathrm{C}$. Vapor pressure was in the range of 5.0 to $8.5 \mathrm{mb}$ and the average value was near 7.0 $\mathrm{mb}$. Wind speed had a maximum value of $5.0 \mathrm{~m} /$ $\mathrm{sec}$, with an average value of around $1.2 \mathrm{~m} / \mathrm{sec}$. The cloud amount was 10 during more than $70 \%$ of the period. This is due to the humid climate in the monsoon season.

As seen in this figure, the air temperature and vapor pressure are quite low due to the high altitude, notwithstanding that this period corresponds to the main ablation period. Wind speed is low in spite of mountain regions. In the monsoon season the large scale wind system in this region is the tropical easterly wind belt which does not often have strong winds. Synoptic scale disturbances rarely come to this region in the summer. So the main wind system in this region is formed by the mountain-valley wind system which cocurs locally in the mountain regions. Strong valley winds are observed at the bottom of large valleys in this region (Inoue, 1976; Ohata et al. 1980). However, at sites near the ridges, the wind speed is usually low due to the characteristics of the mountain-valley wind system. This can be considered as the reason for the low wind speed at the present observation site.

\section{Calculation of heat balance}

The heat balance equation at the glacier surface can be written as follows, as well as ground or ice surface:

$\mathrm{SW}+\mathrm{LW}+\mathrm{S}+\mathrm{L}+\mathrm{C}+\mathrm{V}=\mathrm{M}$
$\mathrm{SW}:$ net shortwave radiation
$\mathrm{LW}:$ net longwave radiation
$\mathrm{S}:$ sensible heat flux
$\mathrm{L} \quad$ : latent heat flux
$\mathrm{C}:$ heat conduction into ice and snow
$\mathrm{V} \quad$ : heat transport by precipitation
$\mathrm{M}:$ heat used in melting ice and snow

This is the heat balance equation which is taken at the ground or ice surface. Heat coming into the surface will be denoted by " + " and going out by" "-".

(1) Net shortwave radiation

Downward shortwave radiation (SW $\downarrow$ ) and reflected shortwave radiation ( $\mathrm{SW} \uparrow$ ) were measured independently. The net shortwave radiation $\mathrm{SW}=$ SW $\downarrow-\mathbf{S W} \uparrow$ was calculated as the absorbed shortwave radiation. In the course of one day, SW was large in the morning and decreased in the midday and afternoon. This is due to the fact that the amount of cloud is small in early morning and gradually increases during the morning. In the afternoon the site was covered with fog or dense orographic clouds.

(2) Net longwave radiation

This term was obtained by the application of empirical equations on I by Robitzsch (1926) and C by Efimova (1961). The equation is

$$
\begin{aligned}
& \mathrm{LW}=-\mathrm{C} \cdot \mathrm{I} \\
& \text { where } \mathrm{I}=\sigma \mathrm{T}^{4}\left[1.0-\frac{(0.135 \mathrm{p}+6.0 \mathrm{e})}{\mathrm{T}}\right] \cdots \cdots \cdots(\mathrm{\cdots}) \\
& \text { and } \mathrm{C}=\left[1.0-\left(0.075 \mathrm{C}_{\mathrm{L}}+0.055 \mathrm{C}_{\mathrm{M}}+0.018 \mathrm{C}_{\mathrm{H}}\right)\right](4) \\
& \sigma \quad: \text { Stefan-Boltzmann constant } \\
& \mathrm{T}: \text { surface temperature }\left({ }^{\circ} \mathrm{K}\right) \\
& \mathrm{p} \quad: \text { air pressure }(\mathrm{mb}) \\
& \mathrm{e}: \text { vapor pressure }(\mathrm{mb}) \\
& \mathrm{C}_{\mathrm{L}}, \mathrm{C}_{\mathrm{M}} \text { and } \mathrm{C}_{\mathrm{H}}: \text { amount of low, middle and } \\
& \quad \text { high level clouds in tenth respectively }
\end{aligned}
$$

I is the net longwave radiation under a clear sky. $\mathrm{C}$ is the factor which shows the effect of the clouds on the net longwave radiation. Air pressure $p$ was taken as $550 \mathrm{mb}$ in all cases. Other parameters such as $T, e, C_{L}, C_{M}$ and $C_{H}$ were obtained for all 1 or 2 hour intervals. The calculated value $I$ did not vary much throughout the observation period, due to minor variations in $\mathrm{T}$ and e. $\mathrm{LW}$ was mostly determined by $\mathrm{C}$ because of frequent change in cloud amount. Fog was seen quite frequently in this area. In these cases LW was taken to be 0 .

(3) Sensible heat flux

Vertical profiles of wind speed and air temperature above the snow or ice surface were obtained as 30-minute means. Most of the wind profiles were logarithmic. However, there were cases when the wind profile showed a maximum near the surface. These corresponded to the katabatic wind flowing down a glacier. These were 
seen mainly in the nighttime. In the derivation of the diffusion coefficient, a logarithmic profile was fitted to the observed profile.

The equations used for the derivation are as follows:

$$
\begin{aligned}
& \mathrm{S}=\rho \mathrm{C}_{\mathrm{p}} \mathrm{ku}_{*} \frac{\mathrm{T}_{2}-\mathrm{T}_{1}}{\ln \left(\mathrm{z}_{2} / \mathrm{z}_{1}\right)} \\
& \mathrm{u}=\frac{\mathrm{u}_{*}}{\mathrm{k}} \ln \left(\frac{\mathrm{z}}{\mathrm{z}_{0}}\right) \\
& \rho \quad: \text { density } \\
& \mathrm{C}_{\mathrm{p}} \quad: \text { specific heat of air under constant } \\
& \quad \quad \text { pressure } \\
& \mathrm{k} \quad: \text { Karman constant } \\
& \mathrm{u}_{*} \quad: \text { friction velocity } \\
& \mathrm{z}_{1}, z_{2}: \text { two heights } \\
& \mathrm{T}_{1}, \mathrm{~T}_{2}: \text { air temperatures at height } \mathrm{z}_{1} \text { and } \mathrm{z}_{2} \\
& \mathrm{z}_{0} \quad: \text { roughness length }
\end{aligned}
$$

In the case when the wind profile was logarithmic, $\mathrm{u}_{*}$ was obtained from the interpolation of wind speed at 4 levels. In the case of katabatic winds, $z_{1}$ was taken as $z_{0}$ and $z_{2}$ was taken as the lowest observing level, which was around $40-50 \mathrm{~cm}$ above the surface. The value $z_{0}$ used in the calculation is the $z_{0}$ obtained before or after the period in question when the profile was logarithmic. Also, $\mathrm{u}=0$ at $\mathrm{z}=\mathrm{z}_{0}$ was assumed. By the above procedure, $\mathrm{u}_{*}$ can be obtained for a katabatic wind. After $\mathrm{u}_{*}$ is obtained, $\mathrm{S}$ can be derived by taking by the air temperature at two levels. In the case of a katabatic wind, $T_{1}$ will be taken as the temperature of the snow/ice surface, which was $0^{\circ} \mathrm{C}$ most of the time.

\section{(4) Latent heat}

Latent heat was calculated in the same manner as for sensible heat. The equation is

$$
\mathbf{L}=\rho \mathbf{L k u} * \frac{\mathrm{q}_{2}-\mathrm{q}_{1}}{\ln \left(\mathrm{z}_{2} / \mathrm{z}_{1}\right)}
$$

where $\mathrm{q} \approx \frac{0.622 \cdot \mathrm{e}}{\mathrm{p}}$

L : latent heat of condensation or evaporation $(\mathrm{cal} / \mathrm{g})$

$\mathrm{q}_{1}, \mathrm{q}_{2}$ : specific humidities at $\mathrm{z}_{1}$ and $\mathrm{z}_{2}$

e : vapor pressure

$\mathrm{L}$ was taken as the latent heat for a wet surface, that is, $597 \mathrm{cal} / \mathrm{g}$. The $\mathrm{u}_{*}$ obtained in eq (6) was used in the case of latent heat. In the case of a katabatic wind, it was treated in the same manner as for sensible heat.
(5) Melting of snow and ice

This was measured by the lowering of snow or ice surface relative to the bottoms of holes drilled into the ice. Three holes were used up to June 20. After that, the number of holes was increased to five, due to the nonuniformity of the surface condition. The density of the ice was assumed to be $0.90 \mathrm{~g} / \mathrm{cm}^{3}$. In a case when the surface was snow, the actual density, which was measured a few times a day, was used. A free water content of $15 \%$ was assumed in the case of melting snow.

(6) Other components

Heat conduction into the ice or snow is considered to be small. The ice temperature was -2 to $-3^{\circ} \mathrm{C}$ a few meters below the surface. Heat transfer by conduction into the ice was estimated to be less than $20 \mathrm{cal} / \mathrm{cm}^{2}$ in the whole observation period. In cases of nocturnal radiative cooling, there were a few cases when the ice near the surface became below $0^{\circ} \mathrm{C}$. However, it was seen in only few nights and the decrease in the ice temperature was small. These cases were also neglected.

Heat transport due to precipitation is also small. The total precipitation was $180 \mathrm{~mm}$ for the period of June 14-29. About $30 \%$ was in the form of snow. This means that $126 \mathrm{~mm}$ was in the form of rain. The average air temperature for that period was around $2.0^{\circ} \mathrm{C}$, so the heat transport to the glacier surface due to rainfall can be considered to be $25 \mathrm{cal} / \mathrm{cm}^{2}$. However, as the temperature of rain is lower than the ambient surface level air temperature the real value is expected to be lower than the above value. So this term was also neglected.

\section{Heat balance for June 14-29}

In Fig. 4, the amount of ablation in the daytime (0600-1800) and nighttime (1800-0600) are shown. From the figure it can be recognized that more than $95 \%$ of ablation occurs in the daytime. This shows that the characteristics of the heat balance in the daytime would be important in understanding the ablation of this glacier.

In Fig. 5, four main components (SW, LW, S and $\mathrm{M}$ ) of the heat balance in the daytime are shown. June 21 and 24 were eliminated due to lack of sufficient data. $L$ was neglected as it was only $0 \sim 3 \mathrm{cal} / \mathrm{cm}^{2} \cdot 12$ hours. Throughout the period, SW and $\mathrm{S}$ were heat sources, and $\mathrm{LW}$ and $M$ were heat sinks. The absolute value of heat source and heat sink for each day showed 


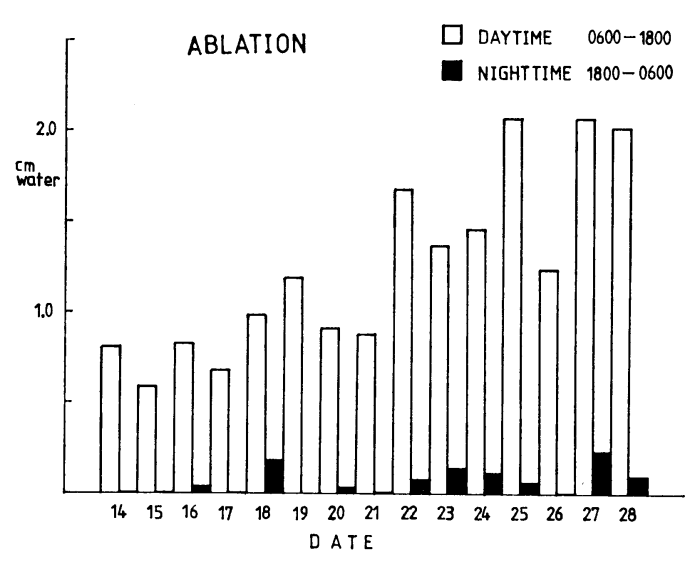

Fig. 4. Amount of ablation in daytime (06001800) and nighttime (1800-0600) for June 14-29.
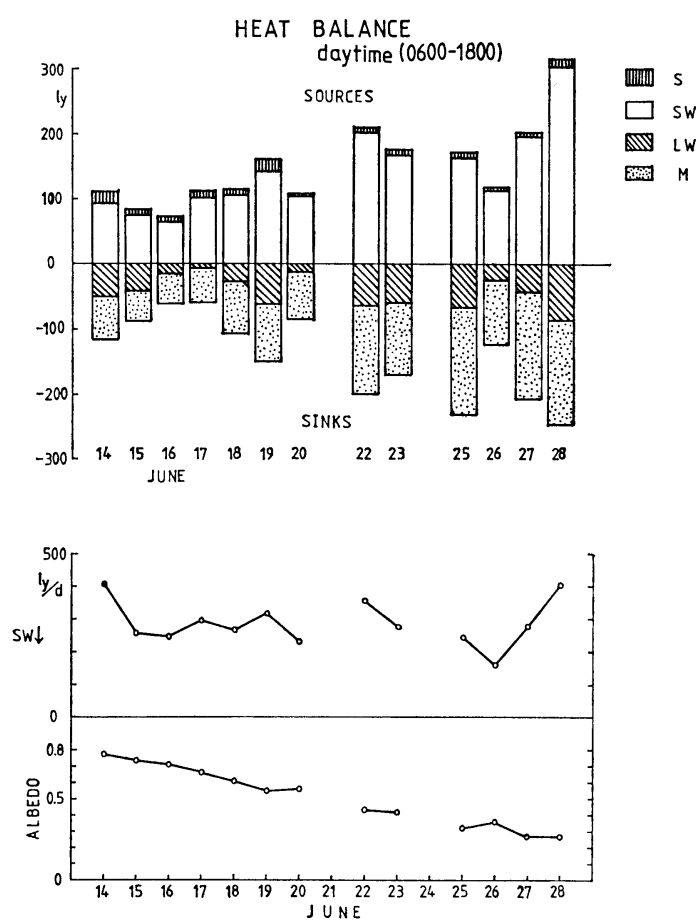

Fig. 5. Daytime heat balance during June 14-29. Four main components are shown. SW is the net shortwave radiation; LW is the net longwave radiation. $\mathrm{S}$ is the sensible heat flux, and $M$ is the heat used for melting.

almost the same value with the exception of June 14 and 28 . The sources were generally larger than the sinks, the difference being $20 \%$ at the most. This quite good agreement shows the applicability of the empirical equation used in the deduction of net longwave radiation, as this term was the only indirectly obtained component.

The general trend of the heat balance term shows that $\mathrm{SW}$ and $\mathrm{M}$ were increasing during the period of June 14 to 28 . To see the reason for the increase in SW, the daily change in downward shortwave radiation (SW $\downarrow$ ) and the albedo of the glacier surface at 1200 NST are shown in Fig. 5. From this figure it can be recognized that there is no significant time variation in SW $\downarrow$, but quite a strong decrease in the value of albedo. The surface albedo is more than 0.5 before June 21 and less than 0.5 after this date. If we compare the albedos of June 14 and June 28, which were 0.77 and 0.27 , it can be recognized that the amount of shortwave radiation that could be absorbed under the same meteorological conditions is approximately 3 times more on June 28 than on June 14 . So, it can be concluded that the increase in SW during the observation period is due to a decrease in the surface albedo. This occurred due to the decrease in the area of the snow layer above the glacier ice. The increase in $\mathrm{M}$ is induced by the increase in SW.

In order to find the relative importance of each component to the heat income, which will be mainly used in melting of ice and snow, the net radiation $\mathrm{SW}+\mathrm{LW}, \mathrm{S}$ and $\mathrm{L}$ for the whole observation period are shown in Table 1. In this table, the total value and the percentage of each component are shown for daytime and whole day periods. The value of the daytime period is the sum of the data shown in Fig. 5. In this case, the 3 components $\mathrm{SW}+\mathrm{LW}, \mathrm{S}$ and $\mathrm{L}$ were calculated independently. The value shown under the whole day period was obtained in a different way. In the nighttime, LW could not be obtained by the empirical equation, due to lack of hourly observations of cloud amount. So LW had to be obtained as the residue of the heat balance equation, that is $\mathbf{L W}=\mathbf{M}-(\mathbf{S}+\mathbf{L}+\mathbf{S W})$. This method was applied to both nighttime and daytime. In general, the heat balance of the whole day is the most useful measure of the characteristics of the heat balance on the glacier surface.

From Table 1, L can be considered to be negligibly small. The percentage of net radiation $(\mathrm{SW}+\mathrm{LW})$ in the total income is $91 \%$ for daytime and $87 \%$ for whole day. This value is quite high for glaciers in the non-polar area. The results obtained at the Greenland Ice Cap (Ambach, 1963), Barnes Ice Cap (Sagar, 1966) and other polar regions show similar percentages, but 
Table 1. Amount and percentage of each component to the heat income for June 14-29. The data for daytime (0600-1800) and whole day periods are showr separately.

\begin{tabular}{c|rr|rr}
\hline & $\begin{array}{c}\text { daytime } \\
\text { cal } / \mathrm{cm}^{2}\end{array}$ & $(\%)$ & $\begin{array}{c}\text { whole day } \\
\mathrm{cal} / \mathrm{cm}^{2}\end{array}$ & $(\%)$ \\
\hline $\mathrm{SW}+\mathrm{LW}$ & 1276 & $(91)$ & 1182 & $(87)$ \\
$\mathrm{S}$ & 116 & $(8)$ & 155 & $(12)$ \\
$\mathrm{L}$ & 10 & $(1)$ & 15 & $(1)$ \\
\hline
\end{tabular}

the result obtained at Vernagtferner, Austria (Hoinkes, 1955) is the only one which shows a similar tendency to the present results in nonpolar regions. As far as the relative importance of the net radiation in the heat income at the surface is considered, this glacier shows the same tendency as glaciers and ice caps in the polar regions.

The fact that the percentage of net radiation in the heat income is quite high at $87 \%$ seems contradictory to the situation of the monsoon season when the cloud amount is high as shown in Fig. 3. However, it can be recognized that the wind speed is low, and air temperature and vapor pressure are near the values at the ice surface, which are $0^{\circ} \mathrm{C}$ and $6.11 \mathrm{mb}$ under melting conditions. Under these conditions the absolute amount of the heat income to the glacier surface can be considered to be small. So the high percentage of net radiation arises from the fact that other components such as $\mathbf{S}$ and $\mathrm{L}$ are small, in spite of cloudy weather.

\section{References}

Ageta, Y., Ohata, T., Tanaka, Y., Ikegami, K. and Higuchi, K. (1980): Mass balance of Glacier AX 010 in Shorong Himal, East Nepal during the summer monsoon season. in this issue.

Ambach, W. (1963): Untersuchungen zum Energieumsatz in der Ablationzone des grönlandischen Inlandeises. Meddelelser on Gr $\phi$ nland, Bd. 174, Nr. 4.

Efimova, N.G. (1961): To the technique of calculating monthly values of effective radiation. Meteorol. Hydrol. No. 10.

Inoue, J. (1976): Climate of Khumbu Himal. Seppyo, 38 Special Issue, 66-73.

Higuchi, K., H. Fushimi, T. Ohata, S. Iwata, K. Yokoyama, H. Higuchi, A. Nagoshi and T. Iozawa (1978): Preliminary report on glacier inventory in the Dudh Kosi Region. Seppyo, 40 Special Issue, 78-83.

Hoinkes, H. (1955): Measurements of ablation and heat balance on alpine glaciers. J. Glaciology, 2, 497-501.

Ohata, T., K. Higuchi and K. Ikegami (1980): Mountain-valley wind system in the Khumbu Himal, East Nepal. in preparation.

Ohata, T., K. Ikegami and K, Higuchi (1980): Albedo of Glacier AX 010 during summer season in Shorong Himal, East Nepal. in this issue.

Robitzsch, M. (1926): Strahlungsstudien. Arb. Obs. Lindenlurg, 15, 194.

Sagar, R.B. (1966): Geographical Bulletin, 8, 3.

Tanaka, Y., Y. Ageta and K. Higuchi (1980): Ice temperature near the surface of Glacier AX 010 in Shorong Himal, East Nepal. inthis issue. 